\title{
Fibroblast Growth Factor 23 and Adverse Clinical Outcomes in Type 2 Diabetes: a Bitter-Sweet Symphony
}

\author{
Stanley M. H. Yeung ${ }^{1} \cdot$ Stephan J. L. Bakker ${ }^{1} \cdot$ Gozewijn D. Laverman $^{2} \cdot$ Martin H. De Borst $^{1}$ \\ Published online: 28 August 2020 \\ (C) The Author(s) 2020
}

\begin{abstract}
Purpose of Review Fibroblast growth factor 23 (FGF23) is a key phosphate-regulating hormone that has been associated with adverse outcomes in patients with chronic kidney disease (CKD). Emerging data suggest that FGF23 plays a specific role in type 2 diabetes, partly independent of kidney function. We aimed to summarize current literature on the associations between FGF23 and outcomes in patients with type 2 diabetes with or without CKD.

Recent Findings Several cohort studies have shown strong associations between plasma FGF23 and cardiovascular outcomes in diabetic CKD. Moreover, recent data suggest that FGF23 are elevated and may also be a risk factor for cardiovascular disease and mortality in type 2 diabetes patients without CKD, although the magnitude of the association is smaller than in CKD patients. Summary Diabetes-related factors may influence plasma FGF23 levels, and a higher FGF23 levels seem to contribute to a higher cardiovascular and mortality risk in patients with type 2 diabetes. Although this risk may be relevant in diabetic individuals with preserved kidney function, it is strongly accentuated in diabetic nephropathy. Future studies should clarify if FGF23 is merely a disease severity marker or a contributor to adverse outcomes in type 2 diabetes and establish if antidiabetic medication can modify FGF23 levels.
\end{abstract}

Keywords Mineral metabolism $\cdot$ Diabetes $\cdot$ Kidney disease $\cdot$ Cardiovascular disease

\section{Introduction}

Fibroblast growth factor 23 (FGF23) is a circulating hormone, predominantly produced by osteocytes, that regulates

This article is part of the Topical Collection on Microvascular Complications-Nephropathy

Martin H. De Borst

m.h.de.borst@umcg.nl

Stanley M. H. Yeung

m.h.yeung@umcg.nl

Stephan J. L. Bakker

s.j.1.bakker@umcg.nl

Gozewijn D. Laverman

g.laverman@zgt.nl

1 Department of Internal Medicine, Division of Nephrology, University of Groningen, University Medical Center Groningen, P.O. Box 30.001, 9700 RB Groningen, the Netherlands

2 Department of Internal Medicine/Nephrology, Ziekenhuisgroep Twente Hospital, Almelo and Hengelo, the Netherlands phosphate excretion by the kidneys and inhibits the synthesis of 1,25 -dihydroxyvitamin- $\mathrm{D}_{3}\left[1^{\circ}\right]$. Initial studies found that deregulations in FGF23 play an important role in the development of bone and mineral disorders. Over 20 years ago, genetic mutations in the FGF23 gene were identified as the cause of autosomal dominant hypophosphatemic rickets (ADHR) [2]. Deregulated FGF23 also plays a role in the etiology of X-linked hypophosphatemic rickets (XLH), another bone disease where renal phosphate wasting plays a main role. Subsequently, novel therapies have been developed including the monoclonal antibody burosumab, which specifically targets FGF23. Clinical trials have now shown that burosumab restores phosphate metabolism, improves growth, and reduces pain in children with XLH [3]; it also seems to improve osteomalacia and skeletal complications in adults [4].

Since promoting renal phosphate excretion is among the main functions of FGF23, and since abnormalities in calcium-phosphate homeostasis are prominent in patients with chronic kidney disease (CKD), it seems plausible that FGF23 is involved in deregulated phosphate homeostasis in these patients. Indeed, many studies over the past years, including 
studies in patients with diabetic nephropathy, have shown that FGF23 levels are increased in CKD patients, most likely in response to a reduced renal capacity to excrete phosphate. In line, after successful kidney transplantation, FGF23 levels decline and transplanted patients may even develop transient hypophosphatemia [5, 6]. Moreover, deregulated FGF23 levels seem to have impact beyond bone disease, as high FGF23 levels have also consistently been associated with a higher risk of cardiovascular and all-cause mortality.

Patients with diabetic nephropathy may display a specific pattern of bone and mineral disturbances, including earlier and more severe increases in FGF23 levels. More recently, emerging data suggested that FGF23 levels may be specifically elevated in patients with type 2 diabetes and be associated with adverse outcomes irrespective of kidney function.

In this review, we will summarize the literature on potential factors driving FGF23 deregulation in diabetes. Subsequently, we address the known associations between FGF23 and outcomes in patients with type 2 diabetes who have either preserved or impaired kidney function.

\section{Elevated FGF23 Levels in Diabetes}

Already in the 1980s, it was shown that patients with diabetic nephropathy have a lower bone mass than non-diabetic CKD patients and that circulating parathyroid hormone (PTH) levels are relatively low $[7,8]$. Also, it has been long known that patients with type 2 diabetes are more prone to fractures and have a higher bone mineral density and an abnormal bone formation rate compared with non-diabetic patients [9-12]. To expand on this, it seems that diabetic patients who have microvascular complications have more severe bone abnormalities compared with patients without microvascular complications, suggesting that microangiopathy might cause bone abnormalities in patients with diabetes $\left[13^{\circ}\right]$. Furthermore, diabetes may also interfere with bone and mineral metabolism. Recent studies have provided a more detailed overview of the spectrum of bone and mineral abnormalities in diabetic nephropathy, including data on FGF23 (Table 1). Initial studies were already suggestive of deregulated FGF23 levels in diabetes, compared with non-diabetic controls, but the limited sample size and heterogeneity of these studies could have confounded the results $[17,18]$. From a large analysis of the Chronic Renal Insufficiency Cohort (CRIC) study, Wahl et al. concluded that the presence of co-existing diabetes was independently associated with higher levels of serum phosphate, PTH, and FGF23 [14••]. Moreover, FGF23 excess was more prevalent earlier in the course of CKD among those with diabetes versus those without diabetes $[14 \bullet \bullet]$. The higher FGF23 levels in diabetic nephropathy may at least partly explain the previously observed association between diabetes and lower $1,25(\mathrm{OH})_{2}$-vitamin D levels [19]. Túñon et al. found similar
FGF23 levels in diabetic vs. non-diabetic patients; this could be explained by the fact that these patients had better kidney function as compared with the CRIC study [15•]. On the other hand, a smaller cohort of prediabetic individuals with normal kidney function displayed significantly higher intact FGF23 levels than obese controls with normal glucose tolerance [16]. In a previous study, we assessed FGF23 in a general population cohort, which also included type 2 diabetes patients $[20 \bullet \cdot$. Here, we specifically analyzed type 2 diabetes patients with an estimated glomerular filtration rate (eGFR) $>60 \mathrm{ml} /$ $\mathrm{min} / 1.73 \mathrm{~m}^{2}$ and matched these patients with individuals without diabetes using propensity score matching analysis (Table 2). After matching, FGF23 levels remained higher in patients with type 2 diabetes than in patients without diabetes (75.6 [IQR 61.3-91.8] vs. 70.8 [IQR 58.0-85.8] RU/mL, respectively, $P<0.001$ ). While the conditions that determine FGF23 levels in patients with diabetes and preserved kidney function are not entirely clear, there seems to be interaction between diabetes and kidney function, with the highest FGF23 levels present in patients with both diabetes and impaired kidney function.

\section{Potential Pathways Driving FGF23 in Diabetes}

Several factors may contribute to deregulated FGF23 in patients with diabetes (Fig. 1). First, patients with diabetic nephropathy seem to have higher serum phosphate levels than matched controls without diabetes [14, 17]. Consequently, FGF23 levels may be elevated in order to keep phosphate balance by stimulating renal phosphate excretion. Second, a recent series of elegant experiments identified glycerol-3phosphate (G3P), a metabolite involved in glycolysis, as a major FGF23 regulator in the setting of acute kidney injury [21••]. Diabetes is characterized by impaired mitochondrial functioning and dysregulated G3P metabolism [22, 23]. Thus, although the initial discovery linking G3P with FGF23 production was in acute kidney injury, this concept also provides an hypothetical link between dysregulated G3P metabolism and FGF23 levels in patients with diabetes. Third, decreased bone formation rates as observed in patients with diabetes could be a stimulus for FGF23 secretion [24]. Fourth, oral glucose loading seems to lower FGF23 levels independent of insulin in patients with an impaired glucose tolerance; whether this is a direct effect of glucose on bone remains to be established [25]. Fifth, patients with diabetes are more prone to develop early tubular injury, prior to a measurable decrease in kidney function or albuminuria [26]. Since FGF23 target tubular epithelial cells to promote phosphaturia, early tubular dysfunction could at least partly contribute to higher FGF23 levels in diabetes [14*0]. Sixth, high levels of glucose could lead to formation of advanced glycation end products (AGEs) [27]. It has been suggested that AGEs could 
Table 1 Overview of studies comparing FGF23 levels in (pre-)diabetes patient with controls

\begin{tabular}{|c|c|c|c|c|c|}
\hline Author & $\mathrm{N}$ & Age (years) & eGFR $\left(\mathrm{ml} / \mathrm{min} / 1.73 \mathrm{~m}^{2}\right)$ & FGF23 assay & FGF23 level \\
\hline \multicolumn{6}{|l|}{ Wahl et al. [14••] } \\
\hline Type 2 diabetes patients & 1820 & $59.5 \pm 9.8$ & $40.7 \pm 12.8$ & C-terminal & 172.4 (114.3-277.2) RU/mL* \\
\hline Non-diabetic controls & 1936 & $57.0 \pm 11.9$ & $44.7 \pm 13.8$ & C-terminal & 121.9 (84.0-198.8) RU/mL \\
\hline \multicolumn{6}{|l|}{ Tuñón et al. [15•] } \\
\hline Type 2 diabetes patients & 173 & 62.8 & $73.8 \pm 20.8$ & C-terminal & $72.2(56.7-104.9) \mathrm{RU} / \mathrm{mL}$ \\
\hline Non-diabetic controls & 531 & 61.0 & $76.5 \pm 18.0$ & C-terminal & 69.9 (54.4-93.7) RU/mL \\
\hline \multicolumn{6}{|l|}{ Gateva et al. [16] } \\
\hline Prediabetes patients & 39 & $50.3 \pm 11.5$ & $124.5 \pm 39.8$ & Intact & $10.4 \pm 10.7 \mathrm{pg} / \mathrm{mL}^{*}$ \\
\hline Non-diabetic obese & 41 & $50.6 \pm 9.7$ & $125.2 \pm 35.6$ & Intact & $5.8 \pm 7.3 \mathrm{pg} / \mathrm{mL}$ \\
\hline
\end{tabular}

$* P<0.05$ vs controlsAbbreviations: $e G F R$ estimated glomerular filtration rate, $c F G F 23$ C-terminal fibroblast growth factor-23

induce a higher FGF23 levels [28]. Seventh, inflammation is a major trigger of FGF23 production [29], and most patients with type 2 diabetes, especially those with obesity, are in a pro-inflammatory state [30]. Eighth, a recent study found that insulin and insulin-like growth factor are strong suppressors of FGF23 in animals and humans [31]. This may explain high FGF23 levels in type 1 diabetes, whereas in type 2 diabetes hyperinsulinaemia may be expected to lead to lower FGF23 levels. Possibly, in type 2 diabetes, the aforementioned proinflammatory state may overrule the suppressive effect of hyperinsulinaemia, ultimately leading to higher FGF23 levels overall.
Elevated FGF23 levels may, in turn, also influence glucose homeostasis. In mice, knockout of the FGF23 gene results in a specific phenotype characterized by, among others, hypoglycemia and increased peripheral insulin sensitivity $[1,32]$. Less is known on the effects of FGF23 on glucose metabolism in humans. A number of smaller studies suggest an inverse correlation between FGF23 levels and insulin sensitivity [33-36], which would be in line with preclinical data. FGF23 is positively associated with resistin, an adipokine, and regulator of insulin resistance, irrespective of kidney function [36, 37]; it should be further addressed whether this

Table 2 Patient characteristics before and after propensity score matching between diabetes patients and non-diabetic controls in the PREVEND study

\begin{tabular}{|c|c|c|c|c|c|c|}
\hline & $\begin{array}{l}\text { Type } 2 \mathrm{DM} \\
(n=288)\end{array}$ & $\begin{array}{l}\text { Non-diabetic controls } \\
(n=5352)\end{array}$ & $\mathrm{P}^{*}$ & $\mathrm{SMD}^{\dagger}$ & $\begin{array}{l}\text { Controls after matching } \\
(n=288)\end{array}$ & SMD \\
\hline C-terminal FGF23, (RU/mL) & $75.6(61.3-91.8)$ & $67.9(55.9-85.0)$ & $<0.001$ & 0.12 & $70.8(58.0-85.8)^{\S}$ & 0.16 \\
\hline Age, $(y r s)^{\ddagger}$ & $62 \pm 10$ & $52 \pm 11$ & $<0.001$ & 0.95 & $61.7 \pm 10.8$ & 0.001 \\
\hline Men, n $(\%)^{*}$ & $144(50)$ & $2462(46)$ & 0.10 & 0.08 & $150(52)$ & 0.04 \\
\hline BMI, $\left(\mathrm{kg} / \mathrm{m}^{2}\right)^{*}$ & $29.4(26.4-32.5)$ & $25.8(23.5-28.7)$ & $<0.001$ & 0.79 & $29.0(26.3-32.9)$ & 0.02 \\
\hline Systolic blood pressure, $(\mathrm{mmHg})$ & $137 \pm 20$ & $124 \pm 18$ & $<0.001$ & 0.68 & $138 \pm 21$ & 0.03 \\
\hline Diastolic blood pressure, $(\mathrm{mmHg})$ & $76 \pm 9$ & $73 \pm 9$ & $<0.001$ & 0.38 & $77 \pm 9$ & 0.04 \\
\hline $\begin{array}{l}\text { eGFR (CKD-EPI) } \\
\left(\mathrm{mL} / \mathrm{min} / 1.73 \mathrm{~m}^{2}\right)^{*}\end{array}$ & $85.4(74.3-98.2)$ & $93.8(80.7-108.4)$ & $<0.001$ & 0.44 & $85.6(74.8-97.0)$ & 0.04 \\
\hline Plasma phosphate, $(\mathrm{mmol} / \mathrm{L})^{*}$ & $1.02 \pm 0.2$ & $1.02 \pm 0.3$ & 0.62 & 0.03 & $1.04 \pm 0.5$ & 0.07 \\
\hline Plasma PTH, (pmol/L) & $5.0(4.2-5.9)$ & $4.9(4.1-5.8)$ & 0.13 & 0.08 & $5.2(4.1-6.1)$ & 0.03 \\
\hline Plasma vitamin D3, $(\mathrm{nmol} / \mathrm{L})^{*}$ & $45.5(33.4-62.5)$ & $53.6(38.3-72.3)$ & $<0.001$ & 0.33 & $47.4(34.3-63.6)$ & 0.04 \\
\hline Urinary P excretion, $(\mathrm{mmol} / 24 \mathrm{~h})^{*}$ & $15(10-21)$ & $15(10-22)$ & 0.23 & 0.07 & $14(10-22)$ & 0.03 \\
\hline
\end{tabular}

Propensity score-based matching (1:1) with all covariates displayed in the table

* $P$ value represents differences between the groups before matching assessed by student's $t$ test or Mann-Whitney U test for nominal and non-normally distributed data, respectively. Chi-squared test was used for categorical variables

$\uparrow$ The standardized mean difference (SMD) compares the difference in the mean in units of the standard deviation of both groups. SMD $<0.1$ after matching represents a negligible difference of the covariate between the groups

$\S P<0.001$ between the groups after propensity score matching using Mann-Whitney U test

Abbreviations: $S M D$ standardized mean difference, $F G F 23$ fibroblast growth factor 23; eGFR estimated glomerular filtration rate, $H S C R P$ high sensitive C-reactive protein, $P T H$ parathyroid hormone, vitamin D3, 25-OH, 25-hydroxycholecalciferol, $P$ phosphate, $A C R$ albumin-to-creatinine ratio 


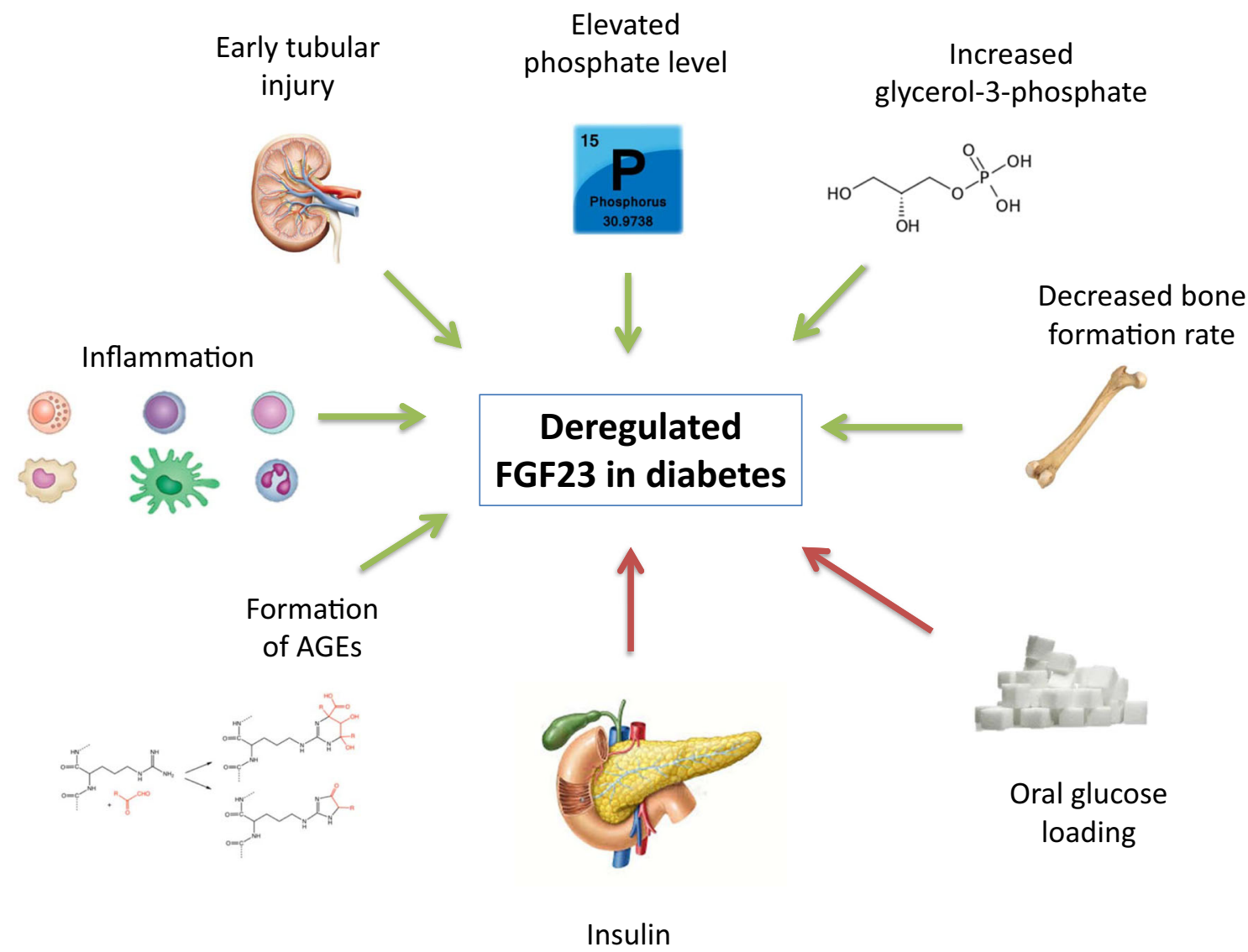

Fig. 1 Overview of factors that may contribute to deregulation of FGF23 in diabetes. Factors that may increase FGF23 levels are indicated with green arrows, while factors that may reduce FGF23 levels are indicated with red arrows

relationship is key to FGF23-induced insulin resistance. Even though the underlying mechanisms are not entirely clear, emerging data indicate that a higher FGF23 level may influence clinical outcomes.

\section{FGF23 in Chronic Kidney Disease}

Although the main focus of this review is on FGF23 in diabetes, most data on the association between FGF23 and clinical outcomes are available in patients with CKD. A landmark study published in 2008 showed that FGF23 levels were independently associated with a higher mortality risk in end-stage kidney disease patients requiring hemodialysis [38]. A wide range of subsequent cohort studies consistently showed that worsening kidney function is accompanied by gradually higher FGF23 levels [39] and that an elevated circulating FGF23 level is associated with a higher mortality risk across stages of CKD [38, 40••] and in kidney transplant recipients [41-43]. Particularly, CKD patients with a rapidly increasing FGF23 level seem to have a higher mortality risk [44]. At least part of the excess mortality seems to be attributable to cardiovascular disease [42] and, more specifically, FGF23 has been linked with a higher risk of (progressive) heart failure [45, 46]. FGF23 has also been associated with a higher risk of kidney function decline in patients with CKD [40••] and with an increased risk of developing CKD in the general population [47••]. Although it remains unclear whether FGF23 or its receptor may be causal factors that promote kidney damage or impair renoprotective therapy [48, 49], emerging data indicate that FGF23 can have detrimental off-target effects on the heart. A meta-analysis observed that in different CKD stages FGF23 is indeed associated with cardiovascular outcomes and mortality, but it was also associated with non-cardiovascular outcomes. This indicates that it may not only have an effect on cardiovascular system, but also on other organ systems [50•].

\section{FGF23 and Outcomes in Diabetes}

As outlined above, in patients with CKD, there seems to be a rather consistent association between FGF23 levels and adverse outcomes across CKD stages, while absolute FGF23 
levels are much higher with more advanced CKD stages. Similarly, these associations appear independent of the primary kidney disease. Several studies have demonstrated that in patients with type 2 diabetes, a higher circulating FGF23 level is associated with an increased risk of all-cause mortality and cardiovascular mortality (Table 3). We also analyzed cardiovascular events as a separate outcome and found that a higher FGF23 level is also associated with a higher risk of cardiovascular events (cardiovascular mortality, unstable angina pectoris, myocardial infarction, transient ischemic attack, cerebrovascular diseases (cerebral infarction or hemorrhage), or heart failure) $[20 \bullet \cdot$.

Interestingly, the association between FGF23 and adverse outcomes in diabetes seems to extend beyond patients with impaired kidney function, as the majority of patients in some of the studies summarized in Table 3 had an eGFR $>60 \mathrm{~mL} / \mathrm{min} / 1.73 \mathrm{~m}^{2}$, and in two studies, the average eGFR was even $>90 \mathrm{~mL} / \mathrm{min} / 1.73 \mathrm{~m}^{2}[53,54]$. This is in line with a specific role for FGF23 in patients with type 2 diabetes, even in patients with preserved or mildly impaired kidney function.

\section{Potential Mechanisms Linking High FGF23 Levels with Outcomes}

FGF23 was observed to be associated with different outcomes, which has led to studies investigating the consequences of excess FGF23 levels. The primary targets of FGF23 in the kidney are NaPi2a/c sodium/phosphate cotransporters, via signaling through the FGF receptor 1 (FGFR1) in conjunction with the canonical co-receptor $\alpha$ klotho. Given its prominent role as a regulator of phosphate homeostasis, FGF23 may contribute to cardiovascular disease through deregulation of phosphate balance, promoting vascular calcification through increased phosphate deposition in the vascular wall. Some [55], but not all [56, 57] studies have linked a higher FGF23 level with vascular calcification. Furthermore, phosphaturia induced by FGF23 may lead to interstitial inflammation, fibrosis, and tubular damage [58]. Although vascular calcification is a prominent feature of cardiovascular disease in diabetes, particularly with co-existing CKD, it does not seem to be the only pathway linking FGF23 with adverse outcomes.

In addition to the regulation of phosphate reabsorption, a higher FGF23 level may also increase renal sodium uptake, leading to volume expansion and hypertension [59-61]. Although these data are not entirely consistent, it may at least partly explain the role of FGF23 in cardiovascular disease as observed in epidemiological studies. Additionally, so-called "off-target" FGF23 signaling routes in different cell types have been identified; for the cardiovascular effects of FGF23 the most relevant off-target signaling pathway seems to be through FGFR4. FGF23 can bind and activate FGFR4 in the heart, independently of $\alpha$-klotho [62], promoting left ventricular hypertrophy [63, 64]. Importantly, from preclinical studies, it seems that pharmacological interference with a specific FGFR4 inhibitor might protect from CKD- and age-related left ventricular hypertrophy [65], opening up novel avenues for intervention aiming to lower the massively elevated cardiovascular risk in CKD. This is particularly relevant since more conventional efforts to lower FGF23, using a phosphate-restricted diet and phosphate binders, have been barely successful [66].

Also worth mentioning is that FGF23 might have an interaction with asymmetric dimethylarginine (ADMA), as it is suggested that both can interfere with the nitric oxide system leading to endothelial dysfunction and atherosclerosis which is associated with CKD progression [67]. High FGF23 levels may also influence $\alpha$-Klotho [68] and as animal studies have shown that a reduction of renal Klotho may result in kidney damage through pro-fibrotic signaling pathways, including

Table 3 Studies assessing the relationship of FGF23 with outcomes in patients with type 2 diabetes

\begin{tabular}{lrlllll}
\hline Author & $\mathrm{N}$ & Follow-up (years) & Age (years) & eGFR (ml/min/1.73 $\left.\mathrm{m}^{2}\right)$ & FGF23 (RU/mL) & Outcome: hazard ratio (95\% CI) \\
\hline Silva et al. [51] & 107 & $2.8 \pm 0.7$ & $57.2 \pm 7.1$ & $52.89 \pm 20.15$ & $135.0 \pm 135.2$ & CV mortality: 2.05 (1.01-8.25) \\
Titan et al. [52] & 55 & $2.6 \pm 0.8$ & $58.4 \pm 10.0$ & $53.0 \pm 20.6$ & $92.0 \pm 42.9$ & ${\text { Composite endpoint }{ }^{1}: 1.09(1.01-1.16)}^{\#}$ \\
Tuñón et al. [15•] & 173 & $2.15 \pm 0.99$ & 62.8 & $73.75 \pm 20.84$ & $72.2(56.7-104.9)$ & Composite endpoint $^{2}: 1.27(1.13-1.43)$ \\
Yeung et al. [20••] & 310 & $5.8(3.3-6.5)$ & $61.5 \pm 8.7$ & $88.5 \pm 14.8$ & $84.2(67.0-117.6)$ & All-cause mortality: $2.55(1.58-4.10)$ \\
& & & & & & MACE: $1.68(1.08-2.61)$ \\
Frimodt et al. [53] & 200 & $6.1(5.9-6.6)$ & $59.9 \pm 9$ & $91.1 \pm 18.3$ & $71(52-108)$ & All-cause mortality: $1.57(1.11-2.18)$ \\
Chan et al. [54] & 513 & $6.6(5.8-7.5)$ & $55.0(49.0-62.0)$ & $91.3(76.4-111.3)$ & $112.4(79.0-165.8)$ & All-cause mortality: $1.74(1.44-2.09)$ \\
\hline
\end{tabular}

${ }^{1}$ Composite endpoint of all-cause mortality, doubling of serum creatinine or requirement for dialysis

${ }^{2}$ Composite endpoint of acute ischemic events (acute coronary syndrome, stroke or transient ischemic attack), heart failure or death

\# Adjusted for potential confounders

Abbreviations: $e G F R$ estimated glomerular filtration rate, $F G F 23$ fibroblast growth factor 23, $C I$ confidence interval, $C V$ cardiovascular, $M A C E$ major adverse cardiac event 
transforming growth factor $\beta 1$ and $\mathrm{Wnt} / \beta$-catenin signaling $[69,70]$.

\section{FGF23-Reducing Strategies}

In the literature, many FGF23-reducing strategies have been extensively studied. Initial studies focused on strategies that lower serum phosphate levels by restricting dietary phosphate intake [71, 72] and/or using phosphate binders [73]. However, discrepant results were observed, as some studies reported no effect on FGF levels of dietary phosphate restriction [74, 75] and/or phosphate binders, alone or in combination with nicotinamide [76, 77]. Therefore, the effectiveness of these strategies remain uncertain. Other approaches include the use of monoclonal antibodies against FGF23 like burosumab. However, in a preclinical study FGF23 monoclonal antibodies applied in a rat model of CKD-mineral and bone disorder led to normalization of bone and mineral markers but increased aortic calcification and mortality, probably due to an incapacity to excrete phosphate, which was already impaired due to the CKD background [78]. Based on these data, it seems unlikely that isolated anti-FGF23 therapy is beneficial in the context of impaired kidney function. The same results were found using a pan-FGFR inhibitor showing that FGF23 is an important phosphate-regulating hormone [79]. Some studies have found that calcimimetics are a viable option to reduce FGF23 levels [80, 81]; however data have so far been limited to patients with end-stage kidney disease. Although theoretically cross-talk between the renin-angiotensin system and FGF23 may lead to changes in FGF23 levels in response to angiotensin-converting enzyme inhibitor (ACEi) or angiotensin receptor blocker (ARB) treatment, so far no studies have demonstrated this convincingly to our knowledge [82]. Interventions aiming to optimize renin-angiogensin-aldostero system (RAAS)-blockade efficacy, such as low-sodium diet or the addition of a thiazide diuretic, may not affect FGF23 levels in diabetic nephropathy [61].

The aforementioned strategies were mostly performed on CKD patients, and thus these strategies have yet to be studied specifically in patients with type 2 diabetes. It is of interest whether antidiabetic medication may influence FGF23 levels in diabetic nephropathy. We recently demonstrated that treatment of diabetic nephropathy patients with the sodiumglucose cotransporter inhibitor (SGLT2i) dapaglifozin led to small but significant increases in serum phosphate, plasma $\mathrm{PTH}$, and FGF23, independent of concomitant changes in eGFR or 24-h albumin excretion [83*0]. A potential mechanism may be that since phosphate and glucose transporters use the same sodium gradient, these transporters may limit each other [84]. Because SGLT2 inhibitors prevent the cotransport and reabsorption of sodium and glucose, the sodium gradient is preserved for the sodium-dependent phosphate transport proteins $\mathrm{NaPi}-2 \mathrm{a}$ and $\mathrm{NaPi}-2 \mathrm{c}$, stimulating tubular phosphate reabsorption [85]. Despite these small effects on mineral metabolism, SGLT2 inhibitors have shown clinically relevant cardiovascular and renal protective effects in diabetic nephropathy, without convincing adverse effects on the bone [85•]. As mentioned before, insulin seems capable to reduce FGF23 levels in human and mice [31]; the clinical value of this observation should be further addressed. Overall, future studies should evaluate the value of antidiabetic medication in reducing FGF23, to further clarify the role of FGF23 in patients with diabetes.

\section{Conclusions}

The current literature indicates that patients with type 2 diabetes, and particularly those with impaired kidney function, generally have an increased FGF23 level compared with individuals without diabetes. This is most likely the consequence of a complex interplay of several deregulated pathways that co-occur in diabetic nephropathy. Importantly, although the underlying pathways have not been fully clarified, a higher FGF23 level has been strongly and consistently linked with a higher risk of (cardiovascular) morbidity and mortality. Interestingly, these associations have been observed in patients with reduced and preserved kidney function, highlighting the prominence of FGF23 as a risk factor in patients with diabetes.

The next question is whether FGF23 plays a causal role in these adverse outcomes or whether it is rather an indicator of an underlying dismal process such as inflammation. In order to address this question in detail, interventions specifically targeting FGF23 need to be studied in diabetic animals and patients with preserved kidney function as many possible therapeutic interventions was applied in the context of impaired kidney function. It may be interesting to study whether such therapy could benefit individuals with diabetes and preserved kidney function, possibly in combination with reduced phosphate intake. Future studies are clearly needed to further advance this field and better understand the deregulations in phosphate metabolism, including FGF23, in patients with diabetes.

Funding Information This work is supported by the Dutch Kidney Foundation (grants CP1601 and 17OKG18).

\section{Compliance with Ethical Standards}

Conflict of Interest Stanley M.H. Yeung, Stephan J.L. Bakker, and Gozewijn D. Laverman each declare no potential conflicts of interest. Martin H. de Borst has consultancy agreements with Amgen, Astra Zeneca, Bayer, Kyowa Kirin, Pharmacosmos, Vifor Fresenius Medical Care Renal Pharma and Sanofi Genzyme and has received grant support from Amgen and Sanofi Genzyme (all outside the submitted work). 
Human and Animal Rights All reported studies/experiments with human or animal subjects performed by the authors have been previously published and complied with all applicable ethical standards (including the Helsinki declaration and its amendments, institutional/national research committee standards, and international/national/institutional guidelines).

Open Access This article is licensed under a Creative Commons Attribution 4.0 International License, which permits use, sharing, adaptation, distribution and reproduction in any medium or format, as long as you give appropriate credit to the original author(s) and the source, provide a link to the Creative Commons licence, and indicate if changes were made. The images or other third party material in this article are included in the article's Creative Commons licence, unless indicated otherwise in a credit line to the material. If material is not included in the article's Creative Commons licence and your intended use is not permitted by statutory regulation or exceeds the permitted use, you will need to obtain permission directly from the copyright holder. To view a copy of this licence, visit http://creativecommons.org/licenses/by/4.0/.

\section{References}

Papers of particular interest, published recently, have been highlighted as:

- Of importance

•• Of major importance

1. Shimada T, Kakitani M, Yamazaki Y, Hasegawa H, Takeuchi Y, Fujita T, et al. Targeted ablation of Fgf23 demonstrates an essential physiological role of FGF23 in phosphate and vitamin D metabolism. J Clin Invest. 2004;113:561-8 Landmark study demonstrating the key role of FGF23 in phosphate homeostasis.

2. XLH Consortium. Autosomal dominant hypophosphataemic rickets is associated with mutations in FGF23. Nat Genet. 2000;26: 345-8.

3. Carpenter TO, Whyte MP, Imel EA, Boot AM, Högler W, Linglart A, et al. Burosumab therapy in children with X-linked hypophosphatemia. N Engl J Med. 2018;378:1987-98.

4. Insogna KL, Rauch F, Kamenický P, Ito N, Kubota T, Nakamura A, et al. Burosumab improved Histomorphometric measures of Osteomalacia in adults with X-linked hypophosphatemia: a phase 3, single-arm, international trial. J Bone Miner Res. 2019;34:218391.

5. Baia LC, Heilberg IP, Navis G, De Borst MH. Phosphate and FGF23 homeostasis after kidney transplantation. Nat Rev Nephrol. 2015;11:656-66

6. van Londen M, Aarts BM, Deetman PEPE, van der Weijden J, Eisenga MFMF, Navis G, et al. Post-transplant hypophosphatemia and the risk of death-censored graft failure and mortality after kidney transplantation. Clin J Am Soc Nephrol. 2017;12:1301-10.

7. Andress DL, Hercz G, Kopp JB, Endres DB, Norris KC, Coburn JW, et al. Bone histomorphometry of renal osteodystrophy in diabetic patients. J Bone Miner Res. 2009;2:525-31.

8. Vincenti F, Arnaud SB, Recker R, Genant H, Amend WJC, Feduska NJ, et al. Parathyroid and bone response of the diabetic patient to uremia. Kidney Int. 1984;25:677-82.

9. Bridges MJ, Moochhala SH, Barbour J, Kelly CA. Influence of diabetes on peripheral bone mineral density in men: a controlled study. Acta Diabetol. 2005;42:82-6.
10. Vestergaard P, Rejnmark L, Mosekilde L. Diabetes and its complications and their relationship with risk of fractures in type 1 and 2 diabetes. Calcif Tissue Int. 2009;84:45-55.

11. Ma L, Oei L, Jiang L, Estrada K, Chen H, Wang Z, et al. Association between bone mineral density and type 2 diabetes mellitus: a meta-analysis of observational studies. Eur J Epidemiol. 2012;27:319-32.

12. Starup-Linde J, Eriksen SA, Lykkeboe S, Handberg A, Vestergaard P. Biochemical markers of bone turnover in diabetes patients-a meta-analysis, and a methodological study on the effects of glucose on bone markers. Osteoporos Int. 2014;25:1697-708.

13. Shanbhogue VV, Hansen S, Frost M, Brixen K, Hermann AP. Bone disease in diabetes: another manifestation of microvascular disease? Lancet Diabetes Endocrinol. 2017;5:827-38 Important review positioning diabetic bone disease as a potential microvascular complication of diabetes.

14.•Wahl P, Xie H, Scialla J, Anderson CAM, Bellovich K, Brecklin C, et al. Earlier onset and greater severity of disordered mineral metabolism in diabetic patients with chronic kidney disease. Diabetes Care. 2012;35:994-1001 Very important study focusing on specific deregulations in mineral metabolism, including FGF23, in a large cohort of patients with diabetes and CKD.

15. Tuñón J, Fernández-Fernández B, Carda R, Pello AM, Cristóbal C, Tarín N, et al. Circulating fibroblast growth factor-23 plasma levels predict adverse cardiovascular outcomes in patients with diabetes mellitus with coronary artery disease. Diabetes Metab Res Rev. 2016;32:685-93 Study showing the association between a higher FGF23 level and increased mortality risk in patients with type 2 diabetes.

16. Gateva A, Assyov Y, Tsakova A, Kamenov Z. Prediabetes is characterized by higher FGF23 levels and higher prevalence of vitamin D deficiency compared to Normal glucose tolerance subjects. Horm Metab Res. 2019;51:106-11.

17. Tanaka H, Hamano T, Fujii N, Tomida K, Matsui I, Mikami S, et al. The impact of diabetes mellitus on vitamin D metabolism in predialysis patients. Bone. 2009;45:949-55.

18. Kojima F, Uchida K, Ogawa T, Tanaka Y, Nitta K. Plasma levels of fibroblast growth factor-23 and mineral metabolism in diabetic and non-diabetic patients on chronic hemodialysis. Int Urol Nephrol. 2008;40:1067-74.

19. Levin A, Bakris GL, Molitch M, Smulders M, Tian J, Williams LA, et al. Prevalence of abnormal serum vitamin D, PTH, calcium, and phosphorus in patients with chronic kidney disease: results of the study to evaluate early kidney disease. Kidney Int. 2007;71:31-8.

20.• Yeung SMH, Binnenmars SH, Gant CM, Navis G, Gansevoort RT, Bakker SJL, et al. Fibroblast growth factor 23 and mortality in patients with type 2 diabetes and normal or mildly impaired kidney function. Diabetes Care. 2019;42:2151-3 In this paper, that specifically focuses on patients with type 2 diabetes and eGFR $>60$ or $>90 \mathrm{~mL} / \mathrm{min} / 1.73 \mathrm{~m} 2$, we showed associations between elevated FGF23 levels and higher risk of cardiovascular morbidity and all-cause mortality.

21.• Simic P, Kim W, Zhou W, Pierce KA, Chang W, Sykes DB, et al. Glycerol-3-phosphate is an FGF23 regulator derived from the injured kidney. J Clin Invest. 2020;130:1513-26 Elegant study that discovers the role of G3P as a regulator of FGF23 production in kidney damage.

22. Giroix M-H, Rasschaert J, Bailbe D, Leclercq-Meyer V, Sener A, Portha B, et al. Impairment of glycerol phosphate shuttle in islets from rats with diabetes induced by neonatal Streptozocin. Diabetes. 1991;40:227-32.

23. Swierczynski J, Zabrocka L, Goyke E, Raczynska S, Adamonis W, Sledzinski Z. Enhanced glycerol 3-phosphate dehydrogenase activity in adipose tissue of obese humans. Mol Cell Biochem. 2003;254:55-9. 
24. Samadfam R, Richard C, Nguyen-Yamamoto L, Bolivar I, Goltzman D. Bone formation regulates circulating concentrations of fibroblast growth factor 23. Endocrinology. 2009;150:4835-45.

25. Ursem SR, Vervloet MG, Büttler RM, Ackermans MT, Oosterwerff MM, Eekhoff EMV, et al. The interrelation between FGF23 and glucose metabolism in humans. J Diabetes Complicat. 2018;32:845-50.

26. Anders H-J, Huber TB, Isermann B, Schiffer M. CKD in diabetes: diabetic kidney disease versus nondiabetic kidney disease. Nat Rev Nephrol. 2018;14:361-77.

27. Yamamoto M, Sugimoto T. Advanced Glycation end products, diabetes, and bone strength. Curr Osteoporos Rep. 2016;14:320-6.

28. Bär L, Wächter K, Wege N, Navarrete Santos A, Simm A, Föller M. Advanced glycation end products stimulate gene expression of fibroblast growth factor 23. Mol Nutr Food Res. 2017;61:1601019.

29. David V, Martin A, Isakova T, Spaulding C, Qi L, Ramirez V, et al. Inflammation and functional iron deficiency regulate fibroblast growth factor 23 production. Kidney Int. 2016;89:135-46.

30. Donath MY, Shoelson SE. Type 2 diabetes as an inflammatory disease. Nat Rev Immunol. 2011;11:98-107.

31. Bär L, Feger M, Fajol A, Klotz L-O, Zeng S, Lang F, et al. Insulin suppresses the production of fibroblast growth factor 23 (FGF23). Proc Natl Acad Sci U S A. 2018;115:5804-9.

32. Hesse M, Fröhlich LF, Zeitz U, Lanske B, Erben RG. Ablation of vitamin $\mathrm{D}$ signaling rescues bone, mineral, and glucose homeostasis in Fgf-23 deficient mice. Matrix Biol. 2007;26:75-84.

33. Wojcik M, Janus D, Dolezal-Oltarzewska K, Drozdz D, Sztefko K, Starzyk JB. The association of FGF23 levels in obese adolescents with insulin sensitivity. J Pediatr Endocrinol Metab. 2012;25:68790.

34. Wojcik M, Dolezal-Oltarzewska K, Janus D, Drozdz D, Sztefko K, Starzyk JB. FGF23 contributes to insulin sensitivity in obese adolescents - preliminary results. Clin Endocrinol. 2012;77:537-40.

35. Garland JS, Holden RM, Ross R, Adams MA, Nolan RL, Hopman $\mathrm{WM}$, et al. Insulin resistance is associated with fibroblast growth Factor-23 in stage 3-5 chronic kidney disease patients. J Diabetes Complicat. 2014;28:61-5.

36. Hanks LJ, Casazza K, Judd SE, Jenny NS, Gutiérrez OM. Associations of fibroblast growth factor- 23 with markers of inflammation, insulin resistance and obesity in adults. PLoS One. 2015;10:e 0122885.

37. Nakashima A, Yokoyama K, Kawanami D, Ohkido I, Urashima M, Utsunomiya $\mathrm{K}$, et al. Association between resistin and fibroblast growth factor 23 in patients with type 2 diabetes mellitus. Sci Rep. 2018;8:13999.

38. Gutierrez OM, Mannstadt M, Isakova T, Rauh-Hain JA, Tamez H, Shah A, et al. Fibroblast growth factor 23 and mortality among patients undergoing hemodialysis. N Engl J Med. 2008;359:584 92.

39. Isakova T, Wahl P, Vargas GS, Gutierrez OM, Scialla J, Xie H, et al. Fibroblast growth factor 23 is elevated before parathyroid hormone and phosphate in chronic kidney disease. Kidney Int. 2011;79:1370-8.

40.• Isakova T, Xie H, Yang W, Xie D, Anderson AH, Scialla J, et al. Fibroblast growth factor 23 and risks of mortality and end-stage renal disease in patients with chronic kidney disease. JAMA. 2011;305:2432-9 Large cohort study in CKD patients that links a higher FGF23 level with mortality and end-stage kidney disease.

41. Wolf M, Molnar MZ, Amaral AP, Czira ME, Rudas A, Ujszaszi A, et al. Elevated fibroblast growth factor 23 is a risk factor for kidney transplant loss and mortality. J Am Soc Nephrol. 2011;22:956-66.

42. Baia LC, Humalda JK, Vervloet MG, Navis G, Bakker SJL, de Borst MH. Fibroblast growth factor 23 and cardiovascular mortality after kidney transplantation. Clin J Am Soc Nephrol. 2013;8:196878.
43. Eisenga MF, van Londen M, Leaf DE, Nolte IM, Navis G, Bakker SJL, et al. C-terminal fibroblast growth factor 23, Iron deficiency, and mortality in renal transplant recipients. J Am Soc Nephrol. 2017;28:3639-46.

44. Isakova T, Cai X, Lee J, Xie D, Wang X, Mehta R, et al. Longitudinal FGF23 trajectories and mortality in patients with CKD. J Am Soc Nephrol. 2018;29:579-90.

45. ter Maaten JM, Voors AA, Damman K, van der Meer P, Anker SD, Cleland JG, et al. Fibroblast growth factor 23 is related to profiles indicating volume overload, poor therapy optimization and prognosis in patients with new-onset and worsening heart failure. Int $\mathrm{J}$ Cardiol. 2018;253:84-90.

46. di Giuseppe R, Buijsse B, Hirche F, Wirth J, Arregui M, Westphal $\mathrm{S}$, et al. Plasma fibroblast growth factor 23, parathyroid hormone, 25-Hydroxyvitamin D3, and risk of heart failure: a prospective, case-cohort study. J Clin Endocrinol Metab. 2014;99:947-55.

47.• De Jong MA, Eisenga MF, van Ballegooijen AJ, Beulens JWJ, Vervloet MG, Navis G, et al. Fibroblast growth factor 23 and new-onset chronic kidney disease in the general population: the Prevention of Renal and Vascular Endstage Disease (PREVEND) study. Nephrol Dial Transplant 2020 Mar 3 Epub ahead of print; doi: $\mathrm{https} / / /$ doi.org/10.1093/ndt/gfz266 Here we showed that in the general population, a higher FGF23 level is associated with an increased risk of developing CKD.

48. De Jong MA, Mirkovic K, Mencke R, Hoenderop JGJG, Bindels RJRJ, Vervloet MGMG, et al. Fibroblast growth factor 23 modifies the pharmacological effects of angiotensin receptor blockade in experimental renal fibrosis. Nephrol Dial Transplant. 2017;32:7380.

49. Taylor A, Yanucil C, Musgrove J, Shi M, Ide S, Souma T, et al. FGFR4 does not contribute to progression of chronic kidney disease. Sci Rep. 2019;9:14023.

50. Marthi A, Donovan K, Haynes R, Wheeler DC, Baigent C, Rooney $\mathrm{CM}$, et al. Fibroblast growth factor-23 and risks of cardiovascular and noncardiovascular diseases: a meta-analysis. J Am Soc Nephrol. 2018;29:2015-27 Important overview of studies linking elevated FGF23 with various outcomes.

51. Silva A, Mendes F, Carias E, Gonçalves R, Fragoso A, Dias C, et al. Plasmatic Klotho and FGF23 levels as biomarkers of CKDassociated cardiac disease in type 2 diabetic patients. Int $\mathrm{J}$ Mol Sci. 2019;20:1536.

52. Titan SM, Zatz R, Graciolli FG, dos Reis LM, Barros RT, Jorgetti $\mathrm{V}$, et al. FGF-23 as a predictor of renal outcome in diabetic nephropathy. Clin J Am Soc Nephrol. 2011;6:241-7.

53. Frimodt-Møller M, von Scholten BJ, Reinhard H, Jacobsen PK, Hansen TW, Persson FI, et al. Growth differentiation factor-15 and fibroblast growth factor- 23 are associated with mortality in type 2 diabetes - an observational follow-up study. PLoS One. 2018;13: e0196634

54. Chan GC, Divers J, Russell GB, Langefeld CD, Wagenknecht LE, Hsu FC, et al. FGF23 concentration and APOL1 genotype are novel predictors of mortality in African Americans with type 2 diabetes. Diabetes Care. 2018:41:178-86.

55. Freedman BI, Divers J, Russell GB, Palmer ND, Bowden DW, Carr JJ, et al. Plasma FGF23 and calcified atherosclerotic plaque in African Americans with type 2 diabetes mellitus. Am J Nephrol. 2015;42:391-401.

56. Scialla JJ, Lau WL, Reilly MP, Isakova T, Yang HY, Crouthamel $\mathrm{MH}$, et al. Fibroblast growth factor 23 is not associated with and does not induce arterial calcification. Kidney Int. 2013;83:1159-68.

57. Hsu JJ, Katz R, Ix JH, de Boer IH, Kestenbaum B, Shlipak MG. Association of fibroblast growth factor-23 with arterial stiffness in the multi-ethnic study of atherosclerosis. Nephrol Dial Transplant. 2014;29:2099-105. 
58. Kuro-o M. Klotho and endocrine fibroblast growth factors: markers of chronic kidney disease progression and cardiovascular complications? Nephrol Dial Transplant. 2019;34:15-21.

59. Andrukhova O, Slavic S, Smorodchenko A, Zeitz U, Shalhoub V, Lanske B, et al. FGF23 regulates renal sodium handling and blood pressure. EMBO Mol Med. 2014;6:744-59.

60. Humalda JK, Lambers Heerspink HJ, Kwakernaak AJ, Slagman MCJ, Waanders F, Vervloet MG, et al. Fibroblast growth factor 23 and the antiproteinuric response to dietary sodium restriction during renin-angiotensin-aldosterone system blockade. Am J Kidney Dis. 2015;65:259-66.

61. Humalda JK, Seiler-Muler S, Kwakernaak AJ, Vervloet MG, Navis $\mathrm{G}$, Fliser D, et al. Response of fibroblast growth factor 23 to volume interventions in arterial hypertension and diabetic nephropathy. Medicine (Baltimore). 2016;95

62. Urakawa I, Yamazaki Y, Shimada T, Iijima K, Hasegawa H, Okawa K, et al. Klotho converts canonical FGF receptor into a specific receptor for FGF23. Nature. 2006;444:770-4.

63. Grabner A, Amaral AP, Schramm K, Singh S, Sloan A, Yanucil C, et al. Activation of cardiac fibroblast growth factor receptor 4 causes left ventricular hypertrophy. Cell Metab. 2015;22:1020-32.

64. Faul C, Amaral AP, Oskouei B, Hu MC, Sloan A, Isakova T, et al. FGF23 induces left ventricular hypertrophy. J Clin Invest. 2011;121:4393-408.

65. Grabner A, Schramm K, Silswal N, Hendrix M, Yanucil C, Czaya B, et al. FGF23/FGFR4-mediated left ventricular hypertrophy is reversible. Sci Rep. 2017;7:1993.

66. Isakova T, Ix JH, Sprague SM, Raphael KL, Fried L, Gassman JJ, et al. Rationale and approaches to phosphate and fibroblast growth factor 23 reduction in CKD. J Am Soc Nephrol. 2015;26:2328-39.

67. Tripepi G, Kollerits B, Leonardis D, Yilmaz MI, Postorino M, Fliser D, et al. Competitive interaction between fibroblast growth factor 23 and asymmetric Dimethylarginine in patients with CKD. J Am Soc Nephrol. 2015;26:935-44.

68. Richter B, Faul C. FGF23 actions on target tissues - with and without Klotho. Front Endocrinol (Lausanne). 2018;9:189.

69. Sugiura H, Yoshida T, Shiohira S, Kohei J, Mitobe M, Kurosu H, et al. Reduced Klotho expression level in kidney aggravates renal interstitial fibrosis. Am J Physiol Renal Physiol. 2012;302:F125264.

70. Zhou L, Li Y, Zhou D, Tan RJ, Liu Y. Loss of Klotho contributes to kidney injury by Derepression of Wnt/ -catenin signaling. J Am Soc Nephrol. 2013;24:771-85.

71. Isakova T, Barchi-Chung A, Enfield G, Smith K, Vargas G, Houston J, et al. Effects of dietary phosphate restriction and phosphate binders on FGF23 levels in CKD. Clin J Am Soc Nephrol. 2013;8:1009-18.

72. Goto S, Nakai K, Kono K, Yonekura Y, Ito J, Fujii H, et al. Dietary phosphorus restriction by a standard low-protein diet decreased serum fibroblast growth factor 23 levels in patients with early and advanced stage chronic kidney disease. Clin Exp Nephrol. 2014;18: 925-31.

73. Gonzalez-Parra E, Gonzalez-Casaus ML, Galán A, MartinezCalero A, Navas V, Rodriguez M, et al. Lanthanum carbonate reduces FGF23 in chronic kidney disease stage 3 patients. Nephrol Dial Transplant. 2011;26:2567-71.
74. Vervloet MG, van Ittersum FJ, Buttler RM, Heijboer AC, Blankenstein MA, ter Wee PM. Effects of dietary phosphate and calcium intake on fibroblast growth factor-23. Clin J Am Soc Nephrol. 2011;6:383-9.

75. Larsson T, Nisbeth U, Ljunggren O, Juppner H, Jonsson KB. Circulating concentration of FGF-23 increases as renal function declines in patients with chronic kidney disease, but does not change in response to variation in phosphate intake in healthy volunteers. Kidney Int. 2003;64:2272-9.

76. Ix JH, Isakova T, Larive B, Raphael KL, Raj DS, Cheung AK, et al. Effects of Nicotinamide and lanthanum carbonate on serum phosphate and fibroblast growth Factor-23 in CKD: the COMBINE trial. J Am Soc Nephrol. 2019;30:1096-108.

77. Block GA, Wheeler DC, Persky MS, Kestenbaum B, Ketteler M, Spiegel DM, et al. Effects of phosphate binders in moderate CKD. J Am Soc Nephrol. 2012;23:1407-15.

78. Shalhoub V, Shatzen EM, Ward SC, Davis J, Stevens J, Bi V, et al. FGF23 neutralization improves chronic kidney disease-associated hyperparathyroidism yet increases mortality. J Clin Invest. 2012;122:2543-53.

79. Yanochko GM, Vitsky A, Heyen JR, Hirakawa B, Lam JL, May J, et al. Pan-FGFR inhibition leads to blockade of FGF23 signaling, soft tissue mineralization, and cardiovascular dysfunction. Toxicol Sci. 2013;135:451-64.

80. Wetmore JB, Liu S, Krebill R, Menard R, Quarles LD. Effects of Cinacalcet and concurrent low-dose vitamin D on FGF23 levels in ESRD. Clin J Am Soc Nephrol. 2010;5:110-6.

81. Moe SM, Chertow GM, Parfrey PS, Kubo Y, Block GA, CorreaRotter R, et al. Cinacalcet, fibroblast growth Factor-23, and cardiovascular disease in hemodialysis: the evaluation of Cinacalcet $\mathrm{HCl}$ therapy to lower cardiovascular events (EVOLVE) trial. Circulation. 2015;132:27-39.

82. De Borst MH, Vervloet MGG, ter Wee PMM, Navis G. Cross talk between the renin-angiotensin-aldosterone system and vitamin DFGF-23-klotho in chronic kidney disease. J Am Soc Nephrol. 2011;22:1603-9.

83.• de Jong MA, Petrykiv SI, Laverman GD, van Herwaarden AE, de Zeeuw D, Bakker SJL, et al. Effects of dapagliflozin on circulating markers of phosphate homeostasis. Clin J Am Soc Nephrol. 2019;14:66-73 Here we report on the effects of the sodium glucose cotransporter-2 inhibitor dapagliflozin on mineral metabolism including FGF23 level.

84. Barrett PQ, Aronson PS. Glucose and alanine inhibition of phosphate transport in renal microvillus membrane vesicles. Am J Physiol Physiol. 1982;242:F126-31.

85. Vinke JSJ, Heerspink HJL, de Borst MH. Effects of sodium glucose cotransporter 2 inhibitors on mineral metabolism in type 2 diabetes mellitus. Curr Opin Nephrol Hypertens. 2019;28:321-7 Overview of the literature on effects of SGLT2 inhibitors on mineral metabolism and bone outcomes.

Publisher's Note Springer Nature remains neutral with regard to jurisdictional claims in published maps and institutional affiliations. 